\title{
Temperature Influence of NiFe Steel Laminations on the Characteristics of Small Slot-less Permanent Magnet Machines
}

\author{
Andreas Krings, Student Member, IEEE, Seyed Ali Mousavi, Oskar Wallmark, Member, IEEE, \\ and Juliette Soulard, Member, IEEE
}

\begin{abstract}
High performance electrical machines can operate at temperatures of $100{ }^{\circ} \mathrm{C}$ and beyond in rotor and stator cores. However, magnetic properties are generally measured at room temperatures around $23^{\circ} \mathrm{C}$ to $25^{\circ} \mathrm{C}$ according to the standards, even if it is known that the magnetization of some materials is substantially influenced by increasing temperatures.

This paper investigates the thermal influence on the magnetic properties and iron losses in the stator cores of small slot-less permanent magnet synchronous machines (PMSMs). The stator stack is made of thin nickel iron (NiFe) lamination sheets. Magnetic measurements of the stator core are conducted for different frequencies and flux densities at several temperatures between $25^{\circ} \mathrm{C}$ and $105^{\circ} \mathrm{C}$. The obtained measurement data is afterwards used in finite element method (FEM) simulations to investigate the influence of the magnetic property change on the machine performance. For the PMSM in consideration, the FEM simulations show that an increased stator core temperature reduces the electromagnetic torque considerably; approximately $1 / 3$ of the torque reduction due to increased rotor magnet and stator core temperatures (from $25^{\circ} \mathrm{C}$ to $100{ }^{\circ} \mathrm{C}$ ) can be attributed to the increased stator core temperature.
\end{abstract}

Index Terms-Iron alloys, loss measurement, magnetic hysteresis, magnetic losses, magnetic materials, permanent magnet machines, soft magnetic materials, thermal effects.

\section{INTRODUCTION}

Temperature investigations on electric steels for electrical machines are relatively rare in literature. It is well known and taken into account in machine simulations that the properties of permanent magnets change with temperature, which in turn changes the machine performance [1]. But the temperature influence on electric steels is commonly neglected in simulations and the electrical machine design process, even if the temperature fluctuation and maximum value are often higher in the stator, compared to the permanent magnets located on the rotor. Therefore, certain used materials can have an essential impact on the machine performance, depending on the machine design.

Magnetic properties for an electrical SiFe steel and two cold rolled general steels are investigated for temperatures up to $700^{\circ} \mathrm{C}$ in [2] and [3]. It is shown, that the magnetic properties of $\mathrm{SiFe}$ are quite stable at typical electrical machine operating temperatures (between $20^{\circ} \mathrm{C}$ to $120^{\circ} \mathrm{C}$ ). Since the conductivity of iron is decreasing with temperature, the eddy current losses are as well decreasing. But for other magnetic materials used in electrical machines, the temperature can have a significant influence on the properties and thus the machine performance and losses. Some general data about the temperature influence on crystalline and amorphous metals can be found in [4]. The magnetic properties of nickel-iron alloys $(\mathrm{NiFe})$ are clearly changing with the temperature.

A. Krings, O. Wallmark, and J. Soulard are with the Department of Electrical Energy Conversion (E2C), KTH Royal Institute of Technology, SE-10044 Stockholm, Sweden (e-mail: andreas.krings@ee.kth.se, oskar.wallmark@ee.kth.se,juliette.soulard@ee.kth.se).

S. Mousavi is with the Department of Electromagnetic Engineering, KTH Royal Institute of Technology, SE-10044 Stockholm, Sweden (e-mail: seyedali.mousavi@ee.kth.se)
$\mathrm{NiFe}$ has the advantage of a very small magnetic field coercitivity and high permeability values. Furthermore, it has low hysteresis and eddy current losses, which makes it a suitable candidate for small high power and low loss electrical machines.

This paper focuses on the temperature influence of NiFe in a small slot-less permanent magnet synchronous machine (PMSM). Since slot-less stator cores do not have magnetic teeth, simple ring core tests, as described in the following sections, have been used to investigate the magnetic material, following the IEC standard [5]. The magnetization curves and losses are measured for different stator cores. Afterwards, the results are used in finite element method (FEM) simulations to investigate the machine performance due to the change of the magnetic properties with temperature.

\section{INVESTIGATED STATOR CORES}

Stator cores of a small, slot-less PMSM are used in this study to investigate the change of the magnetic properties with temperature. Each stator core is $64.5 \mathrm{~mm}$ long and has an outer and inner diameter of $31 \mathrm{~mm}$ and $23.2 \mathrm{~mm}$, respectively. This yields a cross sectional area of the test core of $251.55 \mathrm{~mm}^{2}$ in the circumferential direction. The mean length of the magnetic path is determined to $84.55 \mathrm{~mm}$. A sample core is shown in Fig. 1

The three investigated cores are made from $\mathrm{NiFe}$ electrical steel sheets with thicknesses of $0.1 \mathrm{~mm}$ (1 core) and $0.2 \mathrm{~mm}$ ( 2 cores) and a nickel content of approximately $40 \%$.

Each core is wound with an inner copper winding $N_{2}$ of $0.22 \mathrm{~mm}^{2}$ (FKUX 7/0,2MM) and 8 turns, encased by a stranded wire excitation winding $N_{1}$ of $120 \times 0.1 \mathrm{~mm}^{2}$ (CLI 200/120) and 35 turns. The stranded wire is used to minimize the $\mathrm{dc}$ resistance and to enable the possibility for future 


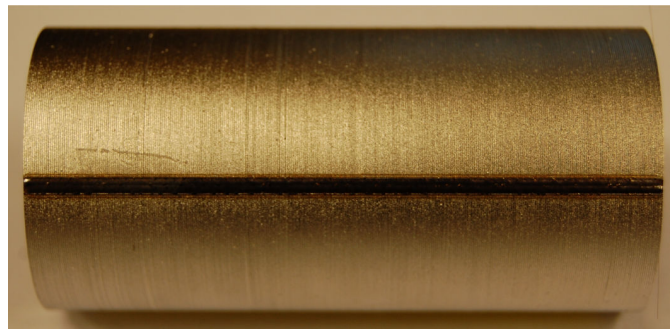

Fig. 1. Investigated stator core.

investigations of the magnetic properties at higher frequencies. One test sample is shown in Fig. 2.

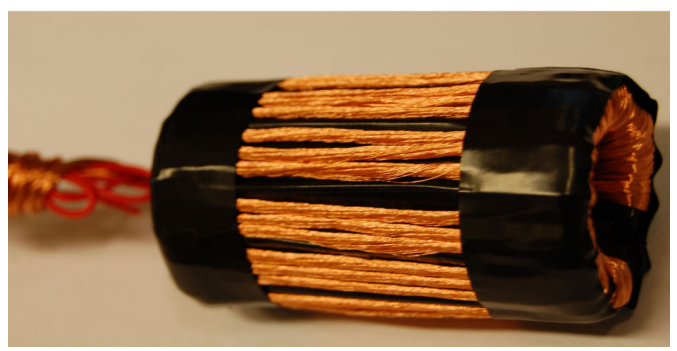

Fig. 2. Investigated test specimen of the stator core.

\section{Measurement And Control system}

The measurement system is built up following chapter 8 of the IEC standard [5]. The control algorithm for the magnetic excitation field is digitally implemented. The only difference in the used measurement setup is, that the flux density is determined from the secondary voltage by an analog flux meter and not integrated digitally.

An overview of the complete measurement setup is shown in Fig. 3, in which the solid lines highlight the electrical power circuit and the dashed lines the measurement and data flow. The later described control algorithm is implemented on a National Instruments CompactRIO system consisting of a Power PC (NI-9022) running the LabVIEW real time operating system (RT System) and an FPGA (NI-9114) for controlling the I/O modules and for initial data processing.

\section{A. Measurement System}

The flux density is determined by a Lakeshore 480 Fluxmeter (FM) which integrates the voltage of the measurement winding (inner winding) of the ring core. Furthermore, a Yokogawa WT1800 power meter (PM) is used to determine the losses in the test sample during the measurement. An isolated material test chamber (Binder FP-115) is used to heat up the stator cores to the desired temperature. Two PT100 temperature sensors are used to check the temperature on the core surface and under the excitation winding.

\section{B. Control System}

The control system for the magnetic measurements is implemented in LabVIEW. Two different control algorithms are

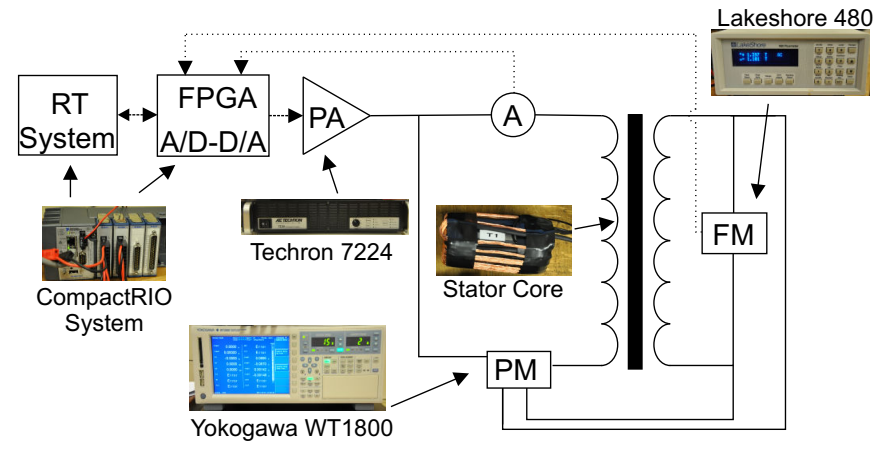

Fig. 3. Overview on the measurement setup, where solid lines indicate the electric power circuit and dashed lines the measurement and data flow.

used for the investigations. For measuring the quasi-static initial magnetization curve, a control algorithm keeping a constant change of the flux density (small constant $\frac{\mathrm{d} B}{\mathrm{~d} t}$ ) has been implemented as described in [6]. It takes approximately $20 \mathrm{~s}$ to reach the maximum point of the magnetization curve, which equals an equivalent full period frequency of $12.5 \mathrm{mHz}$. For AC tests the control algorithm from [7] has been adapted to the system for measuring complete BH hysteresis curves with a sinusoidal flux density at different flux density amplitudes. The LabVIEW system measures and stores the excitation current, the voltage over the measurement winding and the flux density determined by the fluxmeter.

\section{Measurement Principle}

For each measurement, first some initializing loops are run at a high magnetic field strength to determine the voltage offset of the fluxmeter integration. The determined offset stays constant during the measurement and is used in all measurements to remove the integration offset constant from the obtained magnetic flux density value $(B)$. Then, starting from the high initial magnetic field strength, the test samples are slowly demagnetized by decreasing the field strength down to zero over several loop cycles.

For determining the initial magnetization curve, the current, voltage and magnetic flux density as well as the iron loss measurement is started after this demagnetization process. Then, the flux density is linearly increased by keeping the flux density change $\frac{\mathrm{d} B}{\mathrm{~d} t}$ at a small controlled value $(0.01 \mathrm{~T} / \mathrm{s}$ to $0.1 \mathrm{~T} / \mathrm{s}$ ), until the maximum peak current in the excitation winding (approximately $9 \mathrm{~A}$ ) is reached.

For the $\mathrm{AC} \mathrm{BH}$ hysteresis curve measurements, the iterative algorithm is started after the demagnetization process. The algorithm regulates the excitation current waveform until a pure sinusoidal flux density $B$ with a form factor of 1.11 is reached. Then, the recording of the current, voltage and magnetic flux density as well as the iron loss measurement is started and it spans over several periods.

\section{Measurements}

The stator core test specimens are investigated at different temperatures between $27^{\circ} \mathrm{C}$ and $106^{\circ} \mathrm{C}$. The measurements are applied at different magnetic flux densities (up to $1.3 \mathrm{~T}$ ) 
and at frequencies up to $100 \mathrm{~Hz}$. When the core reaches a constant temperature distribution, the magnetic measurements, as described in Section III-C, are started. The maximum deviation between the measurement results of the two stator core samples with $0.2 \mathrm{~mm}$ lamination thickness is less than $0.9 \%$. Thus, it is not possible to visualize the results individually and averaged values are presented in the following plots.

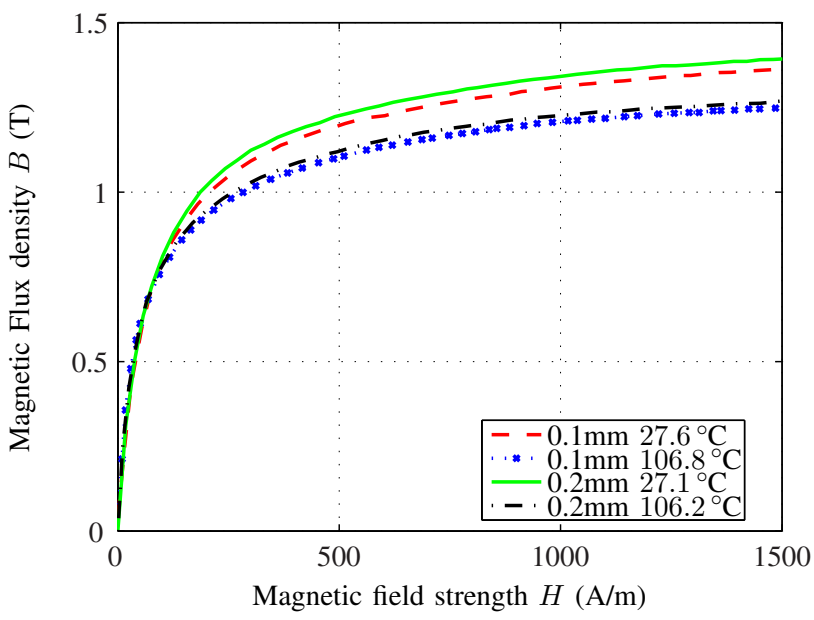

Fig. 4. Initial magnetizing curve for $0.1 \mathrm{~mm}$ and $0.2 \mathrm{~mm} \mathrm{NiFe} \mathrm{lamination}$ sheets with a constant $\frac{\mathrm{d} B}{\mathrm{~d} t}$.

The initial magnetization curves of the test specimens of $0.1 \mathrm{~mm}$ and $0.2 \mathrm{~mm}$ lamination thickness are shown in Fig. 4 at different temperatures. It can be seen that the saturation magnetization is decreased with increasing temperature and that the saturation magnetization is slightly lower for the $0.1 \mathrm{~mm}$ lamination sheets.

The decrease in saturation for complete $\mathrm{BH}$ hysteresis curves at $100 \mathrm{~Hz}$ and a sinusoidal maximum flux density of $1.3 \mathrm{~T}$ is shown for $27.2^{\circ} \mathrm{C}$ and $102.7^{\circ} \mathrm{C}$ in Fig. 5. A magnification of the coercitivity field of Fig. 5 is presented in Fig. 6, where it is shown that the coercitivity decreases with increasing temperature.

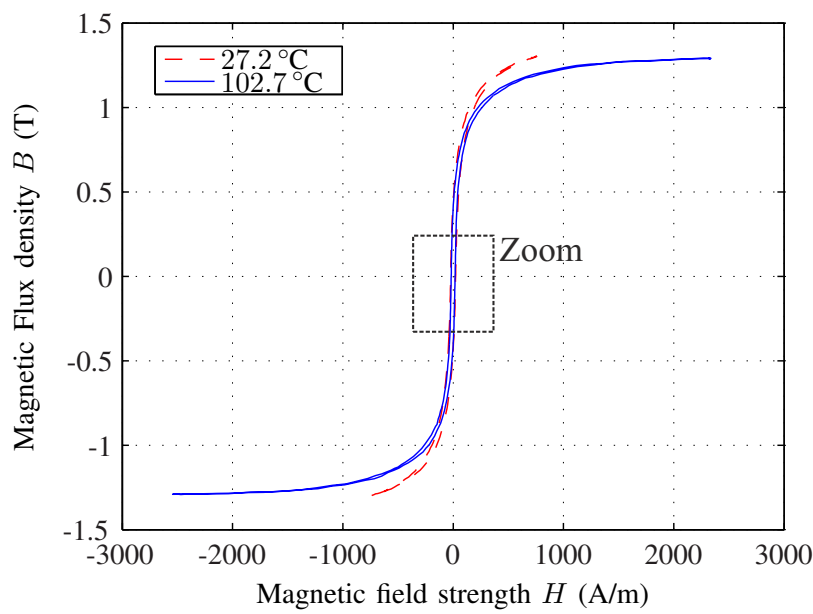

Fig. 5. Complete $\mathrm{BH}$ hysteresis curves for $0.2 \mathrm{~mm}$ lamination sheets at $100 \mathrm{~Hz}$ and a maximum flux density of $1.3 \mathrm{~T}$.

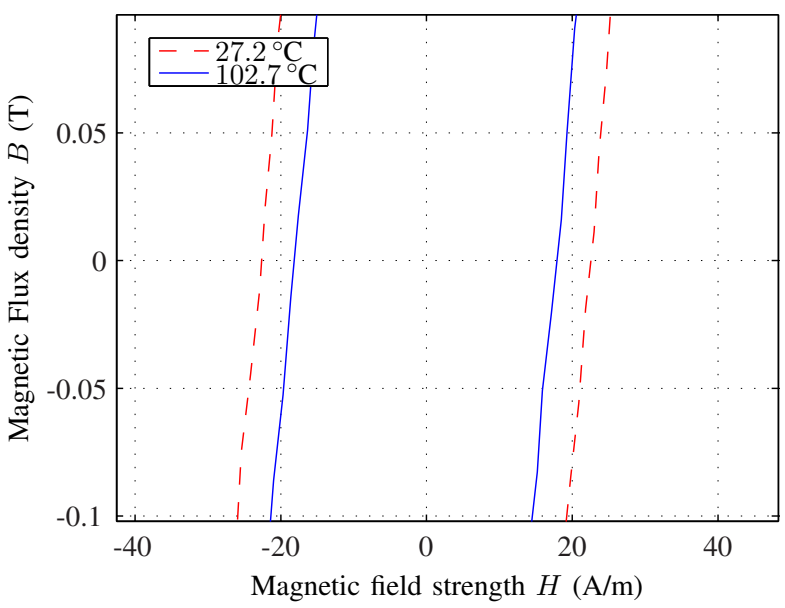

Fig. 6. Zoom of the coercitivity field from Fig. 5.

The change of iron losses with temperature at different frequencies is shown in Fig. 7 for the $0.2 \mathrm{~mm}$ stator cores. The losses decrease with increasing temperature, especially at higher flux densities. At $1.3 \mathrm{~T}$, the losses are equal to $212.2 \mathrm{~mW}$ at $27.2^{\circ} \mathrm{C}$ and $159.2 \mathrm{~mW}$ at $102.7^{\circ} \mathrm{C}$, resulting in a loss decrease of $25 \%$.

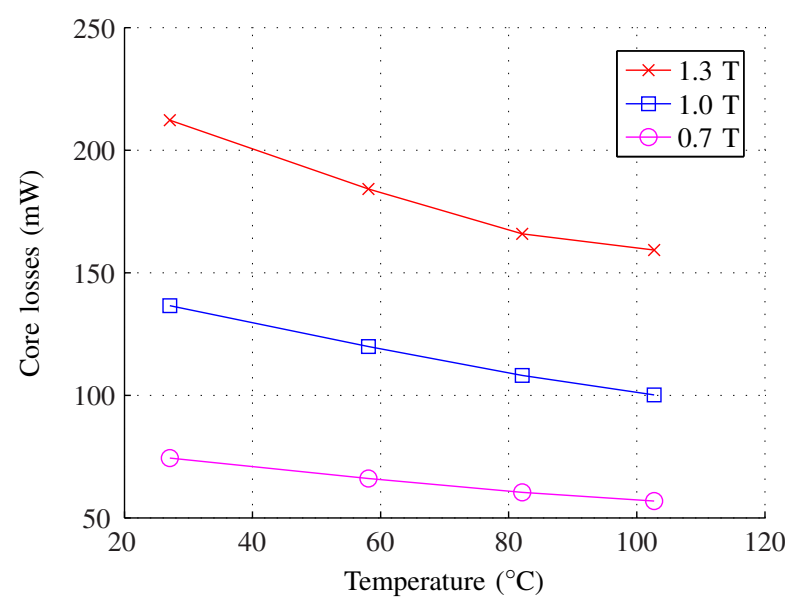

Fig. 7. Iron losses in the $0.2 \mathrm{~mm}$ stator core for different sinusoidal flux densities at $100 \mathrm{~Hz}$.

\section{Finite Element Method Simulations}

The machine in consideration has two poles and a threephase air winding. The rotor consists of several stacked permanent magnet segments in the axial direction with a high remanence flux density $\left(1.31 \mathrm{~T}\right.$ at $\left.20^{\circ} \mathrm{C}\right)$.

Approximately one quarter of the stator core has a partly radial flux density direction. The flux in the rest of the stator core points essentially in the circumferential direction, as can be seen in Fig. 8. Because this flux density distribution is very similar to the distribution obtained during the stator core material investigation in Section IV, these measurements results are used for the stator core material data in the FEM simulations. Furthermore, 2D FEM simulations are sufficient 


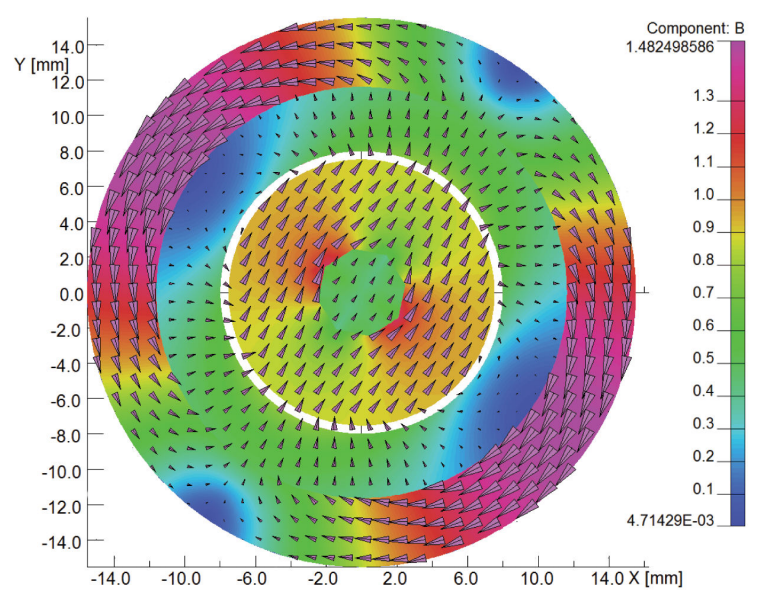

Fig. 8. Flux density distribution and direction in the PMSM at full load.

since the machine has low axial leakage effects, as determined in [8]. All simulations are conducted with a sinusoidal phase current with a peak amplitude of $15 \mathrm{~A}$.

Except from the magnetization curve input data for the stator core material and the permanent magnets on the rotor, all machine parameters in the FEM simulation are kept constant in order to focus on the thermal influence of the magnetic properties on the machine performance. The NiFe initial magnetization curves from temperature measurements between $27^{\circ} \mathrm{C}$ and $106^{\circ} \mathrm{C}$ (see Fig. 4) are applied to the stator core. For the permanent magnets on the rotor, the demagnetization curves for temperatures between $25^{\circ} \mathrm{C}$ and $100{ }^{\circ} \mathrm{C}$ are determined from the manufacturer's data sheet. All other parameters in the simulation are kept constant. The change in torque with the temperature variation is shown in Fig. 9.

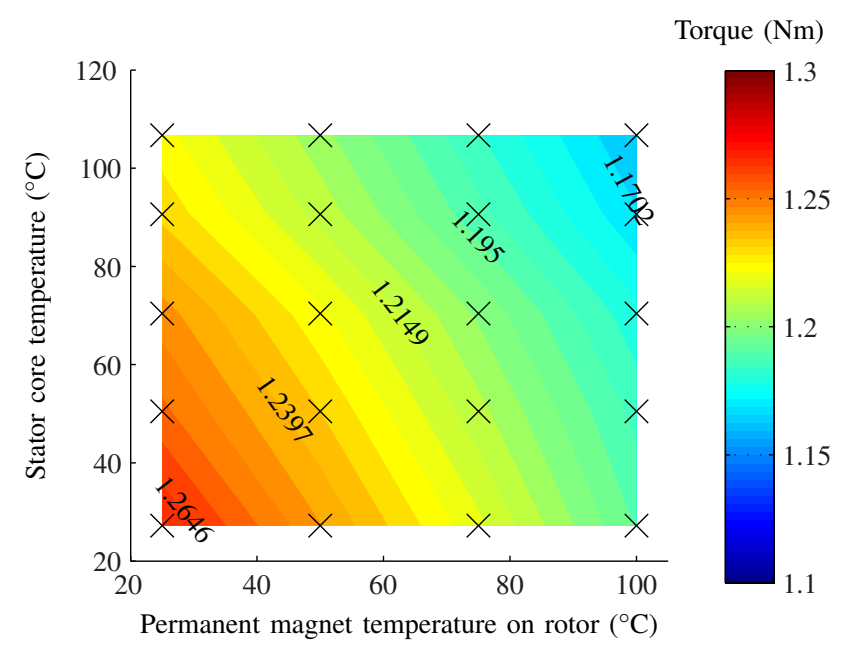

Fig. 9. Electrical output toque of the PMSM as a function of on the stator core and permanent magnet temperature (simulated points marked with ' $\mathrm{X}$ ').

The torque values at the minimum and maximum temperature of the stator core and permanent magnet are given in Table I. It can be seen that even if the temperature influence of the permanent magnet is more pronounced, the change of

TABLE I

TEMPERATURE INFLUENCE ON OUTPUT TORQUE.

\begin{tabular}{|c|c|c|c|}
\hline Stator temperature & Magnet temperature & Torque & Rel. torque \\
\hline $27.1^{\circ} \mathrm{C}$ & $25^{\circ} \mathrm{C}$ & $1.27 \mathrm{Nm}$ & $100 \%$ \\
$27.1^{\circ} \mathrm{C}$ & $100^{\circ} \mathrm{C}$ & $1.19 \mathrm{Nm}$ & $93.7 \%$ \\
$106.2^{\circ} \mathrm{C}$ & $25^{\circ} \mathrm{C}$ & $1.23 \mathrm{Nm}$ & $96.8 \%$ \\
$106.2^{\circ} \mathrm{C}$ & $100^{\circ} \mathrm{C}$ & $1.16 \mathrm{Nm}$ & $91.3 \%$ \\
\hline
\end{tabular}

torque due to the temperature change in the stator core material is not negligible.

\section{CONCLUSIONS}

The presented measurements and FEM simulations give detailed results about the temperature influences on the stator core of a small permanent magnet slot-less synchronous machine. It is shown that the temperature change influences mainly the magnetic properties in the saturation region, whereas the reversible part of the $\mathrm{BH}$ hysteresis curve is hardly influenced. This means that the maximum flux density in the stator core of the machine reduces with an increasing temperature and, in turn, also decreases the maximum output torque of the machine at a constant current. This adds up to the already reduced performance due to the manufacturing influence on the magnetic properties of the lamination [9].

As a conclusion, the variation of the magnetic properties with temperature should be taken into account for $\mathrm{NiFe}$ lamination cores in finite element method (FEM) simulations to achieve a higher modeling accuracy. This is especially important in coupled thermal and electromagnetic simulations, where the permanent magnet parameters are already depending on the temperature.

\section{REFERENCES}

[1] S. Ruoho, J. Kolehmainen, J. Ikaheimo, and A. Arkkio, "Interdependence of demagnetization, loading, and temperature rise in a permanent-magnet synchronous motor," IEEE Trans. Magn., vol. 46, no. 3, pp. 949 -953, Mar. 2010.

[2] N. Takahashi, M. Morishita, D. Miyagi, and M. Nakano, "Examination of magnetic properties of magnetic materials at high temperature using a ring specimen," IEEE Trans. Magn., vol. 46, no. 2, pp. 548 -551, Feb. 2010.

[3] M. Morishita, N. Takahashi, D. Miyagi, and M. Nakano, "Examination of magnetic properties of several magnetic materials at high temperature," Przeglad Elektrotechniczny (Electrical Review), vol. 87, no. 9b/2011, pp. 106-110, 2011.

[4] R. Boll, Weichmagnetische Werkstoffe, 4th ed. Publicis Corporate Publishing, 1990.

[5] "Methods of measurement of the magnetic properties of magnetically soft metallic and powder materials at frequencies in the range $20 \mathrm{~Hz}$ to $200 \mathrm{kHz}$ by the use of ring specimens," International Standard IEC 60404-6:2003.

[6] S. A. Mousavi, "Electromagnetic modeling of power transformers with DC magnetization," Licentiate Thesis, KTH Royal Institute of Technology, Stockholm, Sweden, Nov. 2012.

[7] S. Zurek, P. Marketos, T. Meydan, and A. J. Moses, "Use of novel adaptive digital feedback for magnetic measurements under controlled magnetizing conditions," IEEE Trans. Magn., vol. 41, no. 11, pp. 42424249, Nov. 2005.

[8] O. Wallmark, P. Kjellqvist, and F. Meier, "Analysis of axial leakage in high-speed slotless PM motors for industrial hand tools," IEEE Trans. Ind. Appl., vol. 45, no. 5, pp. 1815 -1820, Oct. 2009.

[9] A. Krings, S. Nategh, O. Wallmark, and J. Soulard, "Influence of the welding process on the magnetic properties of a slot-less permanent magnet synchronous machine stator core," in 2012 XX International Conference on Electrical Machines, Marseille, 2012. 